\title{
Prevalence of Stress, Psychological Distress and Social Support among Clinical Medical Rehabilitation Students in a Nigeria University
}

\author{
Article by Arilewola Abosede Omotola \\ Ph.D., Public Health, Texila American University, Nigeria \\ E-mail: tolabanjo24@yahoo.com
}

\begin{abstract}
Background: University students are faced with challenges on a regular basis and these could be in form of academics, mental, emotional, social, physical, financial and environmental challenges that predisposes them to stress. The objectives of this study are to assess the prevalence of stress, psychological distress and social support received among clinical medical rehabilitation students of Obafemi Awolowo University, Ile-Ife, Nigeria and also assess for any association with demographic variable.

Methods: This study is a cross - sectional study to investigate the prevalence of stress, psychological distress and social support among clinical medical rehabilitation students in a Nigerian University. Self-administered questionnaires consisting of demographic data, perceived stress scale, psychological distress scale, and perceived social support scale questionnaires were used as survey instruments. Data were collated and analyzed using descriptive and inferential statistics. The level of significance was set at $p<0.05$.

Results: The outcome of the study revealed moderate perceived stress as (69.1\%) having the highest percentage, low (27.3\%) and high (3.6\%). Prevalence for mental distress was (47.3\%). Mild distress was (19.1\%), moderate (18.2\%) severe (10.0\%,) and well/normal was (52.7\%). For social support, low support was (9.1\%), moderate (40.9\%) high (50.0\%). Perceived stress had significant correlation with parent marital status and student level in school; $p$ value was 0.039 and 0.038 respectively. Kessler score had significant correlation with students' living arrangement, $p$ value was 0.050, while social support correlated significantly with family economic status of the students, and $p$ was 0.013. No other factors have been found to be significantly correlated.

Conclusions: There is a high prevalence of perceived stress and below average mental distress, symptoms among the university students. Majority had high social support. This is of a great concern in public health. Therefore, there is need for more concerted efforts, preventive measures against mental distress and more sufficient supportive services need be put in place for this group.
\end{abstract}

Keywords: Prevalence, Perceived stress, psychological distress, social supports.

\section{Introduction}

Stress and psychological wellness among college students in the world is a burden of public health. Health Specialist who are in training (medical, physical therapy, nursing and others) are not left out in this (Jacob and Einstein 2016; Koçyiğit et al 2015). This may not be far from the amount and rate of new knowledge they need to absorb. These groups of students are liable to experience increased levels of perceived stress (Jacob and Einstein 2016). Stress can be referred to as the body's response to psychological perception of pressure. Stress leads to hormonal changes and or response in the body. Stress becomes life threatening or dangerous to the body when it is prolonged, or extended or unexpected.

The issue of stress among undergraduates has been an issue in past studies (Elias et al, 2011; Abdulghani 2008; Basson et al, 2015 and Koochaki et al, 2011). Besides coping with social and academic demands, University students due adapt to many psychosocial changes (Shamsuddin et al 2013). The University make available to student psychological and educational development. It has also been reported that entering University can bring a strain or a stress (Elias et al, 2011). The high expectations regarding academic achievement brings about stressful moment. On daily basis students due encounter challenges which contribute to stress and when and if not well managed escalate to 
hamper academic performance, social and emotional wellbeing (Adonizio 2011; Abouserie 2006; Pariat, 2014). Stress is said to result from the interaction between stressors and individual view and reaction to the stressors. The relative amount of stress experienced is based on individual's ability to cope with situations and stressful events (Ross et al, 1999; Devi and Mohan 2015).

Shamsuddin et al, (2013), cited an article that reported high prevalence of stress, anxiety and depression $27.09 \%, 47.1 \%$ and $27.1 \%$ respectively in certain group of Turkish students. He also cited a work that reported females having high level of stress, anxiety and depression and it was attributed to biopsychosocial factors which included factors like social roles and physiological status. The course of study has been found to be associated with these (Shamsuddin et al, 2013). Parents' low socioeconomic status also contributed to depression, anxiety and stress. Students from families with conflicts were also associated with psychological distress. Likewise students from rural areas score higher in assessment of depression, anxiety and stress.

In Nigeria, epidemiological data about psychological morbidity among undergraduate students are not well-known and there is a paucity of research on prevalence perceived stress, psychological distress and social support among undergraduate students in Nigerian universities. Hence, the need for this study.

\section{Significance of study}

The results of this study will help in providing baseline data on prevalence of perceived stress, psychological distress and social support among the clinical medical rehabilitation students of Obafemi Awolowo University, Ile-Ife, Nigeria. The result can serve as awareness to University, or various departments on the student stressors, psychological distress and social support. In addition, the result will also help in identifying associated factors of perceived stress, psychological distress and social support among the clinical medical rehabilitation students of Obafemi Awolowo University, Ile-Ife, Nigeria.

\section{Statement of problem}

Unmanaged stress has been found or can cause mental, physical, emotional and behavioral problems. Students who mismanaged their stress can have psychological distress.

Several studies have shown that university students in other part of the world experience high levels of mental health problems such as stress, anxiety, burnout, psychological distress and depression. In addition, since early detection and quick prevention of these mental health problems among university students are very important in public health practices, hence, the need for this study to examine prevalence of self-reported perceived stress, psychological distress and social support and associated demographic data among university students in my environment.

Furthermore, through my extensive literature search and to the best of my knowledge, there is no formal study conducted on prevalence of perceived stress, psychological distress and social support among medical rehabilitation university students in Ile-Ife and also in Nigeria at large as at the time of conducting this study. Therefore, this study may serve as a baseline study on perceives stress, psychological distress and social support among university students in Ile-Ife and in Nigeria.

\section{Research questions}

The followings were the research questions for this study:

1. How prevalent is stress, psychological distress and social support among medical rehabilitation students of Obafemi Awolowo University, Ile-Ife, Nigeria?

2. What is the self-reported stress level, psychological distress and social support of clinical medical rehabilitation students.

3. Is there any association between socio demographic variables with stress, psychological distress and social support among the medical rehabilitation students of Obafemi Awolowo University, Ile-Ife, Nigeria?

\section{Research objectives}

The followings were the objectives of this study: 
1. To assess the prevalence of perceived stress, psychological distress and social support among the clinical medical rehabilitation students of Obafemi Awolowo University, Ile-Ife, Nigeria.

2. To investigate possible association of perceived stress, psychological distress and social support with demographic variables among the clinical medical rehabilitation students of Obafemi Awolowo University, Ile-Ife, Nigeria.

\section{Literature review}

Increasing reports on stress have been reported among university students in the last years. Many negative academic, emotional and health problems have been linked to stress in university students (Taha et al, 2017). Undergraduate in the medical schools are faced with multiple stressors such as academic overload, lack of leisure time, emotional pressure to maintain good grades, and specific conditions of learning complex medical procedures while working concurrently with patients. (Backovic et al 2012).

Recently stress during medical training is increasingly being reported in published literature. Past studies revealed fairly high levels of distress, such as symptoms of depression and even suicide thoughts among medical undergraduates. The potential negative effects of emotional distress on medical students include impairment of functioning in class-room performance and clinical practice, stress-induced disorders and deteriorating performance. Perceived medical stress has also been linked to current mental distress and to forthcoming health problems. However, there is very little information about the effect of stress on academic performance during medical training (Shah, 2010).

Most students experience distress during medical school. This distress manifests itself in a variety of forms, including burnout, depressive symptoms, stress, poor QOL, and fatigue. The greater the number of forms of distress experienced by an individual student the higher the risk of recent suicidal ideation or serious thoughts of dropping out of medical school. All six global dimensions of distress assessed were independently associated with suicidal ideation or serious thoughts of dropping out of medical school on multivariable analysis. The findings suggest that efforts to identify students whose degree of distress places them at greatest risk for serious consequences must assess for a variety of manifestations of distress. Dyrbye (2011).

Many studies have revealed that students' performance in school, college and university are affected by symptoms of depression, anxiety and stress which may impair their academic achievement leads to deterioration in relationships, marital problems and affects future employment. (Shamsuddin et al, 2013). College student are exposed to a considerable amount of stress, which necessitate successful and constantly changing coping strategy. These were internal and external pressures from the environment to thrive and succeed. (Patriat et al, 2014).

Stress is a mental as well as a physical phenomenon that occurs from cognitive appraisal of a stimulation from individual's interaction with the environment. (Devi and Mohan 2015; Eva et al 2015). Stressors are anything that challenges an individual's adaptability or stimulate an individual's body or mentality (Devi and Mohan 2015). Stress can be caused by environmental factors, psychological, biological and social factors. It can be negative or positive to an individual depending on the strength and persistence of the stress, the individual's personality, cognitive appraisal of the stress and support (Devi and Mohan, 2015). Stress is said to be part and parcel of life. (Kumar and Bhumar, 2013; Kumar and Hegde 2012). A healthy life style is an essential companion to any stress reduction programme. Stress occurs when pressure exceeds beyond its perceived ability to cope. Pertinent to the gender difference in stress experience, it is noted that across many nations, cultures and ethnicities, females are about twice as male to develop depression which is linked to anxiety. (Backovic et al, 2012; Dyrbye et al, 2008). Ffemales face a number of chronic burdens on daily basis as a result of their social status and roles relative to males and these tends to contribute to their higher rates of depressive anxiety (Kumar and Bhukar 2013). Studies suggest that mental health worsens after students begin medical school and remains poor throughout training. On a personal level, this distress due contribute to the issue related to substance abuse, broken relationships, sometimes suicide, and attrition from the profession. With these students, distress has been found to contribute to cynicism. This subsequently affect their care of patients, relationship with faculty, and likewise the medical profession (Dyrbye et al, 2005). Depression among medical students in India represents a 
neglected public health isssue. It is of great importance to prevent the negative effects of depression on individuall's educational attainment and career through early detection and proper interventional measures. (Kumar and Hegde, 2012).

For a student, stress may be caused by failure in academic or sports, financial problems or close friend. Such events that brings about stress are called stressors. (Elias et al 2011). Social support and positive reappraisal among others are found effective. College students are faced with many obstacles which they have to overcome for optimal performance. Stressors such as anxiety, depression, physical health, housing, grades, paper assignments, presentation assignment and group assignment all pose threats to students. Perceived stress as seen in college students sometimes takes the form of academic stress that involves multiple stressors I the likes of academic demands (grades, paper assignments, quizzes/test, presentations assignments, physical health and health related issues and self-imposed type of stressors (Pamela, 2009). Major depressive disorder is associated with substantial symptom severity distributed in the population, with ease in treatment, it seems encouraging, while inadequate treatment will be a serious concern. Emphasis on screening and expansion of treatment needs to be accompanied by a parallel emphasis on treatment quality improvement (Kessler et al, 2003).

Stress is a subjective phenomenon that results from an event that produces physical and psychological pain. It is normal part of everyday life. It may be healthy or unhealthy. Healthy stress is beneficial as a coping strategy to keep awareness, balance and connection. Also, it can help to produce desirable effects such as tolerance of ambiguity, self-confidence, maturity and it may stimulate the acquisition of knowledge and skills (Abdulghani et al. 2014) unhealthy or negative stress, which is referred to as excessive stress can interfere with efficient learning, impair memory, increase anxiety, decrease sleep, causing eating habit related problems lead to accident loneliness, and decrease problem solving abilities. High level of stress may have a negative effect on mastery of the academic curriculum. Stress, health and problems increase during period of undergraduate medical education. This can lead to mental distress and has a negative impact on cognitive functioning and learning. (Abdulghani, 2008). Psychological distress has been reported to be associated with disability and equally with lower academic achievement. university time to be a time of heightened distress, there is need to ensure that students receive the support necessary throughout their studies to enable them successfully complete their degree course, enabling them to negotiate the transition to university and then ultimately into the workforce female more stressed than male( Abouserie 2006).

Psychological distress/Mental distress is a term used by mental health practitioners and also in mental health services, to describe a range of symptoms and experiences of a person's internal life that are commonly held to be troubling, confusing or out of the ordinary. Psychological distress is sometimes defined as a distinct concept often embedded in the context of stress, strain, and distress (Ridner, 2004). Psychological distress can present in various ways and at many levels of severity. But in very general terms it is psychological discomfort. It can be expressed sometimes as sadness, anxiety, distraction, and as cases of psychotic symptoms. It causes varies from a severe stressor, daily stressors, medical illness, or mental illness. It is having a sense of discomfort, feeling unsettled, and usually at a level that is getting in the way of activities of daily living (e.g. work, school, caregiving, self-care). Mild psychological distress can be managed through rest and self-care that includes exercise. But if the distress and the symptoms are really interfering with life or leading to thoughts of harming self or others - intervention is required as quickly as possible - with a licensed medical or mental health professional. Reduced immune response to a certain variety of vaccinations has been associated with psychological stress (Burns et al, 2002). Mental disorders are a majorcontributor to the burden of diseases in all regions of the world (Ekpenyong et al 2011).

Perceived stress is all about feelings about the unpredictability and uncontrollability of one's life, how often one has to deal with irritating hassles, how much change is occurring in one's life, and confidence in one's ability to deal with problems or difficulties. It does not measure frequencies or types of stressful events which have happened to a person, but rather how an individual feels about the general stressfulness of their life and their ability to handle such stress. People may suffer negative life events but appraise the extent or severity of these to different extents as a result of factors such as personality and coping resources. In this way, perceived stress reflects the interaction between an individual and their environment which they appraise (Shah et al, 2010). The Perceived Stress Scale 
(PSS) is a tool for assessing the perception of stress. It measures the degree to which situations in an individual's life are assessed as stressful. It is designed to assess how overloaded, unpredictable and uncontrollable, individuals find their lives.

Social support: Social support is the perception and actuality that one is cared for, has assistance available from other people, and that one is part of a supportive social network. Social support is important for maintaining proper physical and mental health. In all, it showrs that positive social support of high quality can build resilience to stress, help protect against developing trauma-related psychopathology, decrease the functional consequences of trauma-induced disorders, such as posttraumatic stress disorder (PTSD), and reduce medical morbidity and mortality (Ozbay et al, 2007; Fairbrother 2011). Social support is exceptionally important for maintaining good physical and mental health. Overall, it appears that positive social support of high quality can enhance resilience to stress, help protect against developing trauma-related psychopathology, decrease the functional consequences of trauma-induced disorders, such as posttraumatic stress disorder (PTSD), and reduce medical morbidity and mortality. Numerous epidemiological studies have reported that poor social support is associated with the onset and relapse of depression, negative treatment response to dysthymia, seasonality of mood disorder, and the presence of depression comorbid in several medical illnesses, such as multiple sclerosis, cancer, and rheumatoid arthritis (Ozbay et al, 2007). Supportive behaviors are of four types: emotional, instrumental, informational and appraisal (Fairbrother 2011).

Various socio-demographic characteristics such as sex, level of education, and income and financial difficulty, being a house wife and relationship problems are associated with depressive and anxiety disorders. Most studies indicate that sex and socioeconomic status are the most important predictors of these disorders (Mirza and Jenkins 2004,) Females are reported to have higher level of depression, anxiety and stress which can be attributable to biopsychosocial factors such as social roles and physiological status (Dyrbye et al., 2006). Females tend to be on the receiving end in terms of stress, burn out and psychological distress (Glozah 2013; Shah, 2010; Kumar and Hegde; 2012) Moreover, studies have shown that the rates of mental disorders, particularly depression, are associated with various environmental stressors, including family discord (divorce or marital conflict), economic hardship, and stressful life events (Kessler et al., 2003). Some variables such as marital status, urban or rural status, and living arrangements have been found to be related to depressive and anxiety disorders in the literature ( Mirza and Jenkins, 2004).Previous studies showed that belowaverage income was a risk factor for depressive and anxiety disorders (Mirza and Jenkins, 2004). No studies have shown any particular ethnicity to be susceptible to depression, anxiety and stress. However, the minority ethnic group may predispose to these psychological distress (Dyrbye et al., 2007).

\section{Methods}

\section{Research design, study area and population}

A cross sectional descriptive study design was employed for the study and was conducted among undergraduate clinical rehabilitation students those in year 4 and 5 of Obafemi Awolowo University, Ile-Ife, Osun State, Nigeria in April, 2017. Obafemi Awolowo University is a well- known federal Government University located at Ile-Ife, in Osun state, south-western part of Nigeria.

\section{Data collection}

Survey instrument for this study consisted of self-administered questionnaire which was divided into two sections: section one consisted of 9 questions based on demographic variables and source of stress. The section two consisted of three pre tested questionnaire, the Perceived Stress Scale (PSS), Multidimensional Scale of Perceived Social Support (MSPSS), and Kessler Psychological Distress Scale (K10). In administering the scales (PSS, KESSLER10 and MSPSS) the students were asked to rate the extent to which they have experienced various symptoms over the past four weeks. The Perceived Stress Scale is a 10 item self-reported questionnaire designed to assess and measure their feelings and thought in the last one month about stress and has been well accepted worldwide as a reliable and easy-to-use screening instrument. PSS was scored on a 5-point scale with each item ranging from 0 never, 1 almost never, 2 sometimes, 3 fairly often, and 4 very often during the last 
month. In all there are 10 items making a total of 40 . The range is between 0 and 40. KESSLER 10 scale, is a 10 item scale, scored on 5 likert scale, with each item ranging from 1 none of the time, 2 "a little of the time", 3" some of the time", 4" most of the time" and 5 "all of the time". The score range is between 10 and 50. MSPSS scale is a 12 item scale scored on a 7 point scale as 1 very strongly disagree, 2 strongly disagree, 3 mildly disagree, 4 neutral, 5 mildly agree, 6 strongly agree and 7 very strongly agree. The total score ranged from 12 to 84 and then divided by 12 . Score range is from 1 and 7.

\section{Ethical consideration of the study}

Permission to conduct the study was sought and obtained from the head of department and the academic coordinator before embarking on the study. Informed consent was also obtained from every participant before carrying out the study. The confidentiality of information supplied in the questionnaires were assured as no name is required.

\section{Sampling size determination}

The minimum sample size was calculated using Yamane (1967) using the equation $n=N / 1+N(e)^{2}$ , where $\mathrm{n}$ is the sample size, $\mathrm{N}$ is the population size which is 135 clinical medical rehabilitation students and $\mathrm{e}$ is the level of precision at $\pm 5 \%$ (A 95\% confidence level and $\mathrm{P}=0.5$ are assumed for the equation). Therefore $\mathrm{n}=100$. To give allowance for an anticipated non-response rate of $10 \%$ (10 respondents), the sample size was increased by 10 to make 110 respondents. A total of 120 questionnaires were then taken to the students to be distributed for the study. Each respondent was provided with an assurance of confidentiality of information he or she provides in the questionnaire.

\section{Sampling method}

A purposive sample of 110 clinical medical rehabilitation students of Obafemi Awolowo University (60 males and 50 females) were successfully involved using self-administered questionnaires to record their socio-demographic variables and their responses to the Perceived stress scale, (PSS), Kessler psychological distress scale (K10) and Multidimensional scale of perceived social support.(MSPSS) Each respondent was provided with an assurance of confidentiality of information he or she provides in the questionnaire.

\section{Data analysis}

Completed questionnaires were collated and analyzed, descriptive and inferential statistics were used. Statistical analyses were done using the Statistical Package for the Social Sciences, (SPSS software version 17.0). Analysis of socio-demographic variables such as age groups, academic level, ethnicity, gender, living arrangement, academic performance, social life situation, parent marital status, family economic situation and source of stress were presented using frequency distributions and percentages. Means and standard deviation were used to present the scores of the outcome variables which are perceived stress, psychological distress and social support scores. Independent sample t-tests were used to test the differences in means of perceived stress, psychological distress and social support scores by gender and school level variables obtained from the study. Chi square was use to analyze the differences among the PSS, MSPSS and social support in relation to age group, living arrangement, academic performance social life situation, parent marital status and family economic situation. The level of significance was set at $\mathrm{p}<0.05$.

\section{Results}

\section{Demographic characteristics of the respondents}

A total of 110 undergraduate medical rehabilitation students of Obafemi Awolowo University participated in the study. $54.5 \%$ were males $(\mathrm{N}=60)$ and $45.5 \%$ were females $(\mathrm{N}=50)$. They were between the ages of 20 and 33 years. Majority of these participants were in the age group 20- 24 years, $88(80 \%)$. Their mean age was 23.20 years $(\mathrm{SD} \pm 1.94)$. $(59.1 \%)$ of the respondents were in Clinical 1, while $(40.9 \%)$ were in clinical 2. The largest percentage among these students were Yoruba $(85.5 \%)$, majority of them $(47.3 \%)$ were living with friends/in hostels, most of the 
respondents $(78.2 \%)$ were moderately satisfied with their academic performance,. The majority of the respondents $(72.7 \%)$ were moderately satisfied with their social life. The parent marital status of the respondents revealed that majority $(60.9 \%)$ were married and family economic situation of the students the distribution showed that (40.9\%) of them were good, as seen in Table 1.

\section{Respondents' sources of stress}

The respondents were asked to identify exact sources of their stress by ticking either - Yes or -No from a list of 20 stressors. Out the 110 respondents, $6(5.5 \%)$ did not report any stressors, 68 (61.8\%) reported having 1-5 stressors, 27 (24.5\%) had 6-10 stressors, 7 (6.4\%) had 11-15 stressors, and $2(1.8 \%)$ had 16-19 stressors. Frequencies and percentages for the number of stressors selected by respondents are presented in table 2

Table 1. Descriptive statistics of socio-demographic data of the respondents

\begin{tabular}{|c|c|c|c|}
\hline s/no & Variables & Frequency & Percentage $(\%)$ \\
\hline \multirow[t]{4}{*}{1} & \multicolumn{3}{|l|}{ Age (years) } \\
\hline & $20-24$ & 88 & 80.0 \\
\hline & $25-29$ & 21 & 18.9 \\
\hline & $30-34$ & 1 & 0.9 \\
\hline \multirow[t]{3}{*}{2} & \multicolumn{3}{|l|}{ Gender } \\
\hline & Male & 60 & 54.5 \\
\hline & female & 50 & 45.5 \\
\hline \multirow[t]{4}{*}{3} & \multicolumn{3}{|c|}{ Clinical level (year in school) } \\
\hline & Clinical level 1 (year4) & 65 & 59.1 \\
\hline & Clinical level 2 (year5) & 45 & 40.9 \\
\hline & \multicolumn{3}{|l|}{ Ethnicity } \\
\hline \multirow[t]{4}{*}{4} & Yoruba & 94 & 85.5 \\
\hline & Igbo & 6 & 5.5 \\
\hline & Hausa & 1 & 0.9 \\
\hline & others & 9 & 8.2 \\
\hline \multirow[t]{5}{*}{5} & Living arrangement & & \\
\hline & Living with parents & 37 & 33.6 \\
\hline & $\begin{array}{l}\text { Living with friends in } \\
\text { school/in hostels }\end{array}$ & 52 & 47.3 \\
\hline & Living alone & 19 & 17.3 \\
\hline & others & 2 & 1.8 \\
\hline \multirow[t]{5}{*}{6} & Academic performance & & \\
\hline & Highly satisfied & 19 & 17.3 \\
\hline & Moderately satisfied & 86 & 78.2 \\
\hline & Least satisfied & 2 & 1.8 \\
\hline & others & 3 & 2.7 \\
\hline \multirow[t]{5}{*}{7} & \multicolumn{3}{|l|}{ Social life } \\
\hline & Highly satisfied & 21 & 19.1 \\
\hline & Moderately satisfied & 80 & 72.7 \\
\hline & Least satisfied & 7 & 6.4 \\
\hline & others & 2 & 1.8 \\
\hline \multirow[t]{2}{*}{8} & Parent marital status & & \\
\hline & Married & 67 & 60.9 \\
\hline
\end{tabular}


DOI: $10.21522 / \mathrm{TIJPH} .2013 .06 .02 . A r t 018$

ISSN: $2520-3134$

\begin{tabular}{|l|l|l|l|}
\hline & Separated/divorced/widowed & 13 & 11.8 \\
\hline & Never married & 30 & 27.3 \\
\hline 9 & Family economic situation & & \\
\hline & Good & 45 & 40.9 \\
\hline & Moderate & 60 & 54.5 \\
\hline & Poor & 3 & 2.7 \\
\hline & others & 2 & 1.8 \\
\hline
\end{tabular}

Table 2. Table showing the frequency of the stressors as identified by the respondents

\begin{tabular}{|l|l|l|}
\hline Variables & Frequency & Percentages (\%) \\
\hline 0 & 6 & 5.5 \\
\hline 1 & 13 & 11.8 \\
\hline 2 & 19 & 17.3 \\
\hline 3 & 17 & 15.5 \\
\hline 4 & 6 & 5.5 \\
\hline 5 & 13 & 11.8 \\
\hline 6 & 9 & 8.2 \\
\hline 7 & 4 & 3.6 \\
\hline 8 & 2 & 1.8 \\
\hline 9 & 4 & 3.6 \\
\hline 10 & 8 & 7.3 \\
\hline 11 & 2 & 1.8 \\
\hline 13 & 3 & 2.7 \\
\hline 14 & 1 & .9 \\
\hline 15 & 1 & .9 \\
\hline 18 & 1 & .9 \\
\hline 19 & 1 & .9 \\
\hline
\end{tabular}

\section{Prevalence of Stress, psychological distress and social support}

The prevalence of perceived stress, psychological distress and social support among undergraduate clinical medical rehabilitation students of Obafemi Awolowo University were shown in Table 3. Perceived stress is divided into 3 categories of severity, namely, low, moderate and high perceived stress. Psychological distress as normal, mild, moderate, and severe mental disorder. Social support as low, moderate and high support. Mean and standard deviation for perceived stress score obtained was $16.62 \pm 5.94$. Perceived stress scores showed that $(27.3 \%)$ of the respondents have low perceived stress, more than half $(69.1 \%)$ showed moderate perceived stress and 3.6 showed high perceived stress. Also, mean and standard deviation for Psychological distress score was $20.15 \pm 7.47$. Psychological distress scores showed that $(52.7 \%)$ of the respondents are normal (free mental disorder) while the rest (47.3\%) showed prevalence of psychological distress with(19.1\%) as mild mental disorder, $(18.2 \%)$ as moderate, $(10 \%)$ as severe mental disorder. Lastly, mean and standard deviation for social support score was $4.89 \pm 1.34$. Social support scores showed that $(50.0 \%)$ of the respondents have low support. (40.9\%) showed moderate support and $(9.1 \%)$ reported high social support.

Table 3. Prevalence of perceived distress, psychological distress and social support of the respondents, $n=110$

\begin{tabular}{|l|l|l|}
\hline Variables & Frequency & Percentages (\%) \\
\hline Perceived stress scale & & \\
\hline Low perceived stress ( scores 0-13) & 30 & 27.3 \\
\hline Moderate perceived stress ( scores 14-26) & 76 & 69.1 \\
\hline High perceived stress ( scores 27-40) & 4 & 3.6 \\
\hline Mean 16.62, SD =5.94 & \\
\hline
\end{tabular}




\begin{tabular}{|l|l|l|}
\hline $\begin{array}{l}\text { Multidimensional scale of perceived social } \\
\text { support }\end{array}$ & \\
\hline Low support (scores 1- 2.9) & 10 & 9.1 \\
\hline Moderate support ( scores 3 - 5) & 45 & 40.9 \\
\hline High support ( scores 5.1 - 7) & 55 & 50 \\
\hline Mean 4.89, SD =1.34 & \multicolumn{2}{|l|}{} \\
\hline Kessler Psychological distrress scale K10 & 58 & 52.7 \\
\hline Normal /Well ( scores under 20) & 21 & 19.1 \\
\hline Mild mental disorder ( scores 20- 24) & 20 & 18.2 \\
\hline Moderate mental disorder ( scores 25-29) & 11 & 10.0 \\
\hline Severe mental disorder (scores 30 above) & \multicolumn{2}{|l}{} \\
\hline Mean 20.15, SD=7.47 &
\end{tabular}

\section{Association between socio demographic variables and mean scores of PSS, K10 and MSPSS}

Table 4 showed the relationships between socio- demographic factors and mean perceived stress, psychological distress and social support scores among the students. No significant association was found between age, gender, ethnicity, academic performance, living arrangement, social life, family economic situation and the mean perceived stress score. However, there was a significant association between parental marital status and student level with perceived stress score. No significance association was found between psychological distress score with age, gender, student level, ethnicity, academic performance, social life, family economic situation and the mean psychological distress score. However, an association was seen in relation to living arrangement. Similarly, there was no statistical significant relationship between age, gender, student level, ethnicity, academic performance, living arrangement, social life situation, living arrangement and the mean scores of social support.

Statistical significant relationship was found between family economic situation and social support score of the students.

Table4. Socio-demographic factors and their relationship with perceived stress, psychological distress and social support scores

\begin{tabular}{|c|c|c|c|c|}
\hline Variables & $\mathrm{N} \%$ & Perceived stress & $\begin{array}{l}\text { Psychological } \\
\text { distress }\end{array}$ & Social support \\
\hline & & Mean SD & Mean SD & Mean SD \\
\hline All & 110100 & 16.625 .94 & 20.157 .47 & 4.891 .34 \\
\hline \multicolumn{5}{|l|}{ Age } \\
\hline $20-24$ & 8880 & 16.995 .98 & 20.747 .79 & 4.861 .35 \\
\hline $25-29$ & 2119 & 15.195 .78 & 17.435 .42 & 4.941 .35 \\
\hline $30-34$ & 1.9 & $\begin{array}{l}x^{2}=1.754 \\
p=0.781\end{array}$ & $\begin{array}{l}x^{2}=9.129, p=0.1 \\
66\end{array}$ & $\begin{array}{l}\mathrm{x}^{2}=1.048, \mathrm{p}=0.90 \\
2\end{array}$ \\
\hline \multicolumn{5}{|l|}{ Gender } \\
\hline Male & 6054.5 & 17.025 .45 & 20.627 .42 & 4.681 .35 \\
\hline \multirow[t]{2}{*}{ Female } & 5045.5 & 16.146 .49 & 19.587 .56 & 5.141 .29 \\
\hline & & $\begin{array}{l}\mathrm{t}=0.770 \\
\mathrm{p}=0.093\end{array}$ & $\mathrm{t}=0.723, \mathrm{p}=0.471$ & $\begin{array}{l}\mathrm{t}=- \\
1.815, \mathrm{p}=0.072\end{array}$ \\
\hline \multicolumn{5}{|c|}{ Academic level } \\
\hline Clinical 1 & 6559.1 & 15.655 .75 & 19.226 .37 & 4.771 .35 \\
\hline \multirow[t]{2}{*}{ Clinical 2} & 4540.9 & 18.025 .99 & 21.498 .73 & 5.061 .33 \\
\hline & & $t=-$ & $t=-$ & $t=-$ \\
\hline
\end{tabular}


DOI: 10.21522/TIJPH.2013.06.02.Art018

ISSN: $2520-3134$

\begin{tabular}{|c|c|c|c|c|}
\hline & & $2.096, p=0.038$ & $1.580, \mathrm{p}=0.117$ & $1.131, \mathrm{p}=0.260$ \\
\hline \multicolumn{5}{|l|}{ Ethnicity } \\
\hline Yoruba & 9485.5 & 16.575 .99 & 20.347 .60 & 4.871 .33 \\
\hline Igbo & 65.5 & 18.175 .46 & 18.675 .99 & 5.030 .88 \\
\hline Hausa & 1.9 & 15.115 .56 & 18.227 .24 & 4.711 .69 \\
\hline Others & 98.2 & $\begin{array}{l}x^{2}=2.681 \\
p=0.848\end{array}$ & $\begin{array}{l}x^{2}=8.564, p=0.47 \\
8\end{array}$ & $\begin{array}{l}\mathrm{x}^{2}=4.802, \mathrm{p}=0.56 \\
9\end{array}$ \\
\hline \multicolumn{5}{|c|}{ Living arrangement } \\
\hline $\begin{array}{l}\text { Living with } \\
\text { parent }\end{array}$ & 3733.6 & 17.195 .93 & 18.877 .66 & 4.971 .56 \\
\hline $\begin{array}{l}\text { Living with } \\
\text { friends/hostel }\end{array}$ & 5247.3 & 16.816 .06 & 20.317 .23 & 4.741 .33 \\
\hline Living alone & 1917.3 & 16.214 .80 & 23.007 .19 & 5.180 .84 \\
\hline \multirow[t]{2}{*}{ Nil response } & 21.8 & 5.001 .41 & 12.502 .12 & 4.201 .13 \\
\hline & & $\begin{array}{l}x^{2}=7.649, p=0.2 \\
65\end{array}$ & $\begin{array}{l}\mathrm{x}^{2}=16.945, \mathrm{p}=0.0 \\
50\end{array}$ & $\begin{array}{l}\mathrm{x}^{2}=8.749, \mathrm{p}=0.18 \\
8\end{array}$ \\
\hline \multicolumn{5}{|c|}{ Academic performance } \\
\hline $\begin{array}{l}\text { Highly } \\
\text { satisfied }\end{array}$ & 1917.3 & 15.056 .06 & 19.425 .38 & 5.461 .42 \\
\hline $\begin{array}{l}\text { Moderately } \\
\text { satisfied }\end{array}$ & 8678.2 & 16.895 .92 & 20.197 .85 & 4.791 .27 \\
\hline \multirow[t]{2}{*}{$\begin{array}{l}\text { Least } \\
\text { satisfied }\end{array}$} & 21.8 & 20.007 .07 & 21.0012 .73 & 2.752 .05 \\
\hline & 32.7 & 16.676 .35 & 22.678 .08 & 5.300 .96 \\
\hline \multicolumn{5}{|c|}{ Social life situation } \\
\hline $\begin{array}{l}\text { Highly } \\
\text { satisfied }\end{array}$ & 2119.1 & 15.956 .43 & 17.766 .04 & 5.121 .71 \\
\hline $\begin{array}{l}\text { Moderately } \\
\text { satisfied }\end{array}$ & 8072.7 & 16.635 .67 & 20.287 .48 & 4.791 .26 \\
\hline $\begin{array}{l}\text { Least } \\
\text { satisfied }\end{array}$ & 76.4 & 20.215 .56 & 28.006 .50 & 4.770 .89 \\
\hline \multirow[t]{2}{*}{ Nil response } & 21.8 & 10.5010 .61 & 12.503 .54 & 6.350 .07 \\
\hline & & $\begin{array}{l}\mathrm{x}^{2}=4.284, \mathrm{p}=0.6 \\
38\end{array}$ & $\begin{array}{l}x^{2}=15.813, p=0.0 \\
71\end{array}$ & $\begin{array}{l}x^{2}=7.814, p=0.25 \\
2\end{array}$ \\
\hline \multicolumn{5}{|c|}{ Parental marital status } \\
\hline Married & 6760.9 & 16.366 .45 & 19.467 .13 & 4.991 .27 \\
\hline $\begin{array}{l}\text { Separated/div } \\
\text { orced/widow } \\
\text { ed }\end{array}$ & 1311.8 & 17.236 .78 & 23.159 .56 & 5.081 .52 \\
\hline \multirow{2}{*}{$\begin{array}{l}\text { Never } \\
\text { married }\end{array}$} & 3027.3 & 16.934 .27 & 20.377 .15 & 4.571 .41 \\
\hline & & $\begin{array}{l}\mathrm{x}^{2}=10.116, \mathrm{p}=0 \\
039\end{array}$ & $\begin{array}{l}x^{2}=4.382, p=0.62 \\
5\end{array}$ & $\begin{array}{l}x^{2}=1.977, p=0.74 \\
0\end{array}$ \\
\hline \multicolumn{5}{|c|}{ Family economic situation } \\
\hline Good & 4540.9 & 15.315 .78 & 18.876 .74 & 4.901 .51 \\
\hline Moderate & 6054.5 & 17.576 .03 & 21.287 .81 & 4.981 .10 \\
\hline
\end{tabular}




\begin{tabular}{|l|l|l|l|l|}
\hline Poor & 332.7 & 19.674 .16 & 17.6710 .69 & 2.831 .55 \\
\hline Nil response & 21.8 & 13.002 .83 & 18.509 .19 & 4.802 .40 \\
\hline & & $\begin{array}{l}\mathrm{x}^{2}=3.599, \mathrm{p}=0.7 \\
31\end{array}$ & $\begin{array}{l}\mathrm{x}^{2}=10.376, \mathrm{p}=0.3 \\
21\end{array}$ & $\begin{array}{l}\mathrm{x}^{2}=16.121, \mathrm{p}=0.0 \\
13\end{array}$ \\
\hline
\end{tabular}

\section{Discussion}

The objective of this study is to assess the prevalence of perceived stress, psychological distress and social support among clinical rehabilitation students of Obafemi Awolowo University, Ile-Ife, Nigeria. In this study, the prevalence obtained for the presence of perceived stress, psychological distress and social support were $69.1 \%, 47.3 \%$ and 50\% respectively. Prevalence of depression was $71.25 \%$ in a study reported by Kumar and Hegde (2012). (80.0\%) had mild - moderate degree of depression. Koochaki et al (2011), found $61.3 \%$ (18.0\% mild, $22.5 \%$ moderate and $20.8 \%$ severe) the result obtained from this study $47.3 \%$ (19.1\% for mild, $18.2 \%$ for moderate and $10.0 \%$ for severe) is lower compared to Koochaki's result. There was no significant difference in the stress level between clinical 1 and 2 students or between sexes. This is in line with the work of Abdulghani, 2008 and Koochaki et al, 2012. This result contradict the work of (Basson et al,2015; Shah et al, 2010; Saleh et al, 2017 and Shamsuddin et al, 2013) who reported significant difference in sexes, with females more affected. Males more affected as reported by Kumar and Hedge 2012. Glozah 2013 reported females are more depressed. The result also showed that prevalence of perceived stress is higher in comparison to that of psychological distress among the clinical medical rehabilitation students of Obafemi Awolowo University, Ile- Ife, Nigeria. The prevalence of stress was lower in this study compared to a study by Koochaki et al 2011. The outcome shows that prevalence of stress exists at lower rate among the clinical medical rehabilitation students in this study as compared to some other environment outside Nigeria.

In this study, no statistical significant relationship was found between age and perceived stress in line with the work of Koochaki et al 2011. There was also no significance relationship between PSS and gender in line with Koochaki et al 2011. Prevalence of elevated psychological distress were found in $30 \%$ of randomly sampled undergraduate students attending 16 different universities in Canada. Adlaf et al, (2001) and Stallman et al, (2010) reported estimated prevalence of 19.2\% with 67.4\% reporting subsyndromal symptoms. Also, $77.6 \%$ into moderate stress, $10.4 \%$ serious stress. Adonizio (2011) reported prevalence of $10 \%$ and $40 \%$ in mental health problems in studies conducted in the 1970s and 1980s and the mean depression, anxiety and stress scores among American students.

\section{Limitation}

This study has some limitations. The questionnaire used for this study depends upon self- reported measures. Therefore, the accuracy of the information provided in the questionnaire can be influenced, mistaken perceptions of a situation by the respondents. This limitation was controlled to some extent by making the questionnaire a closed ended type. Also, since the study was conducted in one university among the clinical medical rehabilitation students of the institution, the outcome of this study cannot be generalized on the entire population of all university students in Nigeria.

\section{Conclusion}

This study shows that there is high prevalence of perceived stress and slight below average psychological distress among undergraduate clinical rehabilitation students of Obafemi Awolowo University, Ile-Ife, Nigeria and about half of the population considered had high support. The implication of this is that students having stress or perceived stress with associated psychological distress, are to have more support from necessary quarters. Neglected public health problem in institutes of higher learning, can lead to adverse effects on the mental health quality of life and the need to have more support from necessary quarters. In this study, perceived stress was found to be associated with parental marital status and student level. Psychological distress was associated with living arrangement while social support was associated with family economic status. No other factors have been found to be significantly associated. 
DOI: $10.21522 / \mathrm{TIJPH} .2013 .06 .02 . A r t 018$

ISSN: $2520-3134$

\section{Recommendation}

The followings are therefore recommended:

1. There is need for mandatory workshops and seminars explaining anxiety, stress and coping methods at all year of study.

2. Need for concerted efforts and provision of necessary supports for the undergraduate by the people who surrounds them and from the environment

3. There is also need for much more attention to the psychological wellbeing of undergraduate students in order to improve their quality of life.

4. Preventive screening, mental health services and relevant coping strategies should be put in place as an important aspect of college education, and this should be regular basis so as to prevent mental health problems among students admitted into the universities.

5. Early diagnosis, treatment and counseling as necessary to vulnerable students

\section{References}

[1]. Abdulghani Hamza. M (2008): Stress and depression among medical students: A cross sectional study at a medical college in Saudi Arabia. Pakistan Journal of Medical Sciences. Quarterly, Vol 24, No 1, $12-17$.

[2]. Adiaf EM, Gliksman L, Demers A, Newton Taylor B (2001): The prevalence of elevated psychological distress among Canadian undergraduates: findings from the 1998 Canadian campus survey. J AM College of Health Sept, 50 (2), $67-72$

[3]. Anna C Phillips (2013): Perceived stress. Encyclopaedia of Behavioral Medicine. pg 1453 - 1454.

[4]. Azza Ali Taha, Etemad AA El-Shereef, Wedad Althobaiti, Mai Muaimedh Algethami (2017): Study of perceived stress among female students, Taif University, Saudi Arabia. America Journal of Public health research. 5(3): 50 - 55. doi. 10.12691/ajphr-5-3-1.

[5]. Basson W.J., Nel K.A. and Bhat S.B. (2015): Stress amongst dental students at an emerging medical university. J Psychology 6(1): 87 - 90.

[6]. Bridgette Bewick, Gina Kontsopoulou, Jeremy Miles, Esther Slaa and Michael Barkham (2010): Changes in undergraduate students' psychological wellbeing as they progress through university. Studies in higher education. Vol. 35, Issue 6, pages $633-645$.

[7]. Burns VE, Drayson M, Ring C, Carrol D (2002): Perceived stress and psychological wellbeing are associated with antibody status after meningitis C conjugate vaccination. Psychosom Med. Nov - Dec, 64(6): $963-70$.

[8]. Dalia Saleh, Nathalie Camart and Lucia Romo (2017): Predictors of stress in college students. Front. Psychology. Vol. 8: 19. January.

[9]. Dusan V. Backovic, Jelema IIic Zivojinovic, Jadrankamak Simovic, Milos Maksimovic (2012): Gender differences in academic stress and burnout among medical students in final years of education. Psychiatria Danubina. Vol. 24, No 2. Pages 175 - 181.

[10]. Dyrbye L.N. et al 2006. Systematic Review of depression, anxiety and other indications of psychological distress among US and Canadian medical students. "Academic Medicine 81(4): 354 - 373.

[11]. Ekpenyong C.E., Davis K.J., Akpan U.P. and Daniel N.E. (2011): Academic stress and menstrual disorders among female undergraduates in Uyo, South Estern Nigeria. The need for heath education. Niger. J. Physiol. Sc: 26 (December) 193 - 198. Mental disorders are a major contribution to the burden of diseases in all regions of the world.

[12]. Eliza Omar Eva, Md Zakiru Islam, Abu Syed Md Mosaddek, Md Faizur Rahman, Rini Juliet Rozario, Af Md Hassan Iftekhar, Tarafder Shahniam Ahmed, Iffat Jahan, Rabiu Abubakar, Wan Putri Elena Han Dali, Mohammed S Razzaque, Rahat Bin Habib and Mainul Haque (2015): Prevalence of stress among medical students: a comparative study between public and private medical schools in Bangladesh. BMC Research Notes 8.327. DOI: 10.1186/S 13104-015-1295-5.

[13]. Faith Ozbay, Douglas C Johnson, Eleni Dimoulas, C.A. Morgan Dennis Charney and Steven Southwick (2007): Social Support and resilience to stress: from Neurobiology to clinical practice. Psychiatry (Edgmont). May; 4(5): 35 - 40.

[14]. Figen Kocyigit, Emel Dikbas Torun, Ummuhan Bas Aslan (2015): Anxiety, depression, physical activity and quality of life in student physical therapists; A cross sectional study. American Journal of Educational Research Vol. 3, No 10A, pp 26 - 29. http://pubs.sciepub.com/education/3/10A/4 
[15]. Frank Patrick Addonizio (2011): Stress, coping, social support and psychological distress among MSW students. University of South Carolina, ProQuest Disertations Publishing, UMI Number: 3481178.

[16]. Franklin N. Glozah (2013). Effects of academic stress and perceived social support on the psychological wellbeing of adolescents in Ghana. Open Journal of Medical Psychology. 2. $143-150$. http://dx.doi.org/10.4236/ojmp.2013.24022.

[17]. Ganeshs Kumar, Animesh Jain and Supriya Hegde (2012): Prevalence of depression and its associated factors using Beck Depression Inventory among students of a medical college in Karnataka. Indian J. Psychiatry. July - September. 54(3); 223 - 226.

[18]. Habibah Elias, Wong Siew Ping and Maria Chong Abdullah (2011): Stress and Academic Achievement among Undergraduate Students in University Putra Malaysia. Procedia - Social and Behavioural Sciences 29: $646-655$.

[19]. Helen M. Stallman (2010): Psychological distress in university students: A comparison with general population data. Australian Psychologist. Vol 45, Issue 4 page 249 - 257.

[20]. Khadijah Shamsuddin, Fariza Fadzil, Wan Salwina, Wan Ismail, Shamsul Azhar Shah, Khairani Omar, Noor Azimah Muhammad, Aida Jaffar, Aniza Ismail, Raynuha Madadevan (2013): Correlates of depression, anxiety and stress among Malaysian University Students. Asian Journal of Psychiatry, 6, 318 - 323.

[21]. Koochaki GM, Charkazi A, Hasanzadel A, Saedain M, Qorbani M, Marjani A (2011): Prevalence of stress among Iranian medical students: a questionnaire survey. East Mediterranean Health J. July; 17(7); 593 - 8.

[22]. Lakyntiew Pariat, Angelyne Rynjah, Joplin. M.G. Kharjana (2014). Stress levels of college students: Interrelationship between stressors and coping strategies. IOSR Journal of Humanities and Social Science, Vol. 19. Issue 8; Ver. III (Aug). Pg 40 - 46.

[23]. Liselotte N. Dyrbye, Matthew R. Thomas, Standford Massie, David V. Power, Anne Eacker, William Harper, Steven Durning, Christine Moutler, Daniel, W. Szydlo, Paul J. Novotry, Jeff A. Sloan and Talt, D.Shanafelt. (2011). Patterns of distress in US medical students (2011): Medical Teacher Vol. 33: 834 - 839.

[24]. Liselotte N. Dyrbye, Matthew R. Thomas, Standford Massie, David V. Power, Anne Eacker, William Harper, Steven Durning, Christine Moutler, Daniel, W. Szydlo, Paul J. Novotry, Jeff A. Sloan and Talt, D. Shanafelt. (2008).Medical student Burnout and suicidal ideation. Annals Internal Medicine Medical Teacher Vol. 149 (5): $334-341$.

[25]. Lisolette N. Dyrbye, Matthew R. Thomas, Tait D. Shanafekt (2005): Medical Students Distress: causes, consequences and proposed solutions. Vol. 80, Issue 12, pages 1613 - 1622. Elsevier.

[26]. Mohsin Shah, Shahid Hasan, Samina Malik and Chandrashekhar T Sreeramaredoly (2010). Perceived stress, sources and severity of stress among medical undergraduates in a Pakistan Medical School. BMC Med Educ. Vol. 10:2.

[27]. Nicole Fairbrother (2011): Social Support. Issues of visions Journal Vol. 6(4) pg 7.

[28]. Nirza I, Jenkins R (2004): Risk factors, prevalence and treatment of anxiety and depression disorders in Pakistan: Systematic review BMJ. April. Vol 328 (7443): 794.

[29]. Pamela L. (2009): Premenstrual syndrome and academic stress in emerging adulthood women. Available at (http://www.nursingarizona.edu/library/091) as cited by Ekpenyong et al 2011.

[30]. Purna Prabhakar Nandamuri and Gowthami Ch. Sources of academic stress - A study on management students, http://JMS.nonolympictime.org/Articles/4.pdf.

[31]. Reda Abouserie (2006): Sources and levels of stress in relation to locus of control and self-esteem in university students http://dx.doc.org/10.1080/0144341940140306 published online, pg 323-330.

[32]. Reda Abouserie (2009): Sources and levels of stress in relation to locus of control and self-esteem in university students. Educational Psychology. (An international journal of experimental educational psychology). Vol. 14, Issue 3, pages $323-330$.

[33]. Richard Cooke, Bridgette M. Bewick, Michael Barkham, Margaret Bradley and Kerry Audin (2007): Measuring, monitoring and managing the psychological wellbeing of the first year students. British Journal of Guidance and Counselling, Vol. 34, Issue 4, pages 505 - 517.

[34]. Ridner SH (2004): Psychological distress; Concept analysis. J. Advanced Nursing. March, Vol. 45(5):536 -545 .

[35]. Ronald C. Kessler, Patricial Berglund Olga Demler, Jin R, Koretz D, Merikanga SKR, Rush AJ, Walter's EE, Wang PS (2003). June. Vol. 289(23): 3095 - 105. 
DOI: $10.21522 /$ TIJPH.2013.06.02.Art018

ISSN: $2520-3134$

[36]. Ross, Shannon E, Niebling, Bradley C and Heckert, Teresa M. 1999. Sources of stress among college students. College Student Journal; June, vol. 33, Issue 2, pg 312, 6p.

[37]. Sanjeev Kumar and J.P. Bhukar (2013): Stress level and coping strategies of college students. Journal of Physical Education and Sports Management, Vol. 4(1): pp 5 - 11, January.

[38]. Sathya R. Devi and Shaj Mohan (2015): A study on stress and its effects on college students. International Journal of Scientific Engineering and Applied Science (IJSEAS) - Vol. 1, Issue 7, Oct.

[39]. Sherry A. Benton, John M. Robertson, Wen-Chin Tseng, Fred B-Newton and Stephen L. Benton (2003): Changes in counselling centre client problem across 13 years. Professional Psychology; Research and Practice. Vol 34, No 1, 66- 72 .

[40]. Tamar Jacob and Ofira Einstein (2016): Stress among bachelor of physical therapy students in Israel during clinical practice and its association with academic achievements - Result of a longitudinal study. The Internet Journal of Allied Health Sciences and Practice, January, 12; 14(1), Article 9.

[41]. Tomlinson M, Grimsrud, Stein. J. Dan Anna T., William David R, Myer Landon (2009). The epidemiology of major depression in South Africa: Results from the South African Stress and Health Study: South African Medical J, 99: 368 - 373.

[42]. Uma K and Manikardan K (2013): Influence of locus of control, self-esteem and sex on academic stress among adolescents. Guru Journal of Behavioral and Social Sciences. Vol. 1, Issue 4 (Oct - Dec) 186- 193.

[43]. Wong. P.T.P, Wong L.C.J. and Scott G. (2006). The positive psychology of transformation beyond stress and coping. In Wong, P.T.P. and Wong, L.C.J. (Eds), Handbook of multicultural perspectives on stress and coping. New York, Nt: Springer. 